\title{
CAN WE PREDICT CO-OPERATION WITH ORTHODONTIC TREATMENT?
}

\author{
S Matthew, SpR, Orthodontics \\ Morecambe Bay Hospitals Trust
}

\section{INTRODUCTION}

Successful orthodontic treatment depends to a large extent on the cooperation of the patient. Orthodontic appliances worn incorrectly or for an insufficient time are unlikely to achieve optimum results. Frequent breakages, of either fixed or removable appliances, extend the time in treatment by many months and are inefficient in terms of time and resources. Inadequate tooth brushing and oral hygiene can lead to decalcification and permanent scars on the teeth and at worst cavities and dental caries.

It would make life simple if we could pick winners in advance!

These statistics show that overall nearly 1:5 patients fail to complete treatment successfully and in the 15-17 year age group this rises to more than 1:3. An incomplete or discontinued treatment is an unsatisfactory outcome for all concerned: patient, orthodontic clinician and provider. These figures have important implications in terms of NHS resources as over $£ 112$ million is spent on orthodontic treatment every year (Dental Practice Board, 2002) (1) $^{(1)}$

\begin{tabular}{|l|l|c|}
\hline General dental services & Haynes 1982 & $20 \%$ \\
\hline & Richmond \& Andrews $1995^{(3)}$ & $15 \%$ \\
\hline Hospital services & Murray $1989^{(4)}$ & $13 \%$ \\
\hline 15 -17-year-olds & Haynes $1982^{(2)}$ & $40 \%$ \\
\hline
\end{tabular}

Table I Percentage discontinuation rates for orthodontic treatment

I was interested in finding out if I could predict at the start of treatment those patients who would complete successfully.

\section{AIMS}

The aim of my MSc study was to evaluate whether sociodental indicators for orthodontics would predict completion of and compliance with orthodontic treatment. Sociodental indicators are multiple social and dental variables we can measure. Can we predict at the start which subjects will complete the treatment?

\section{LITERATURE REVIEW}

I reviewed the literature and found that it is virtually impossible to predict patient compliance using conventional measures such as age, socio-economic factors, pain, oral hygiene or progress in the early stages of treatment. Many influencing factors such as plaque score and attendance for appointments only become apparent once the patient has started treatment. Information that is collected at the start of a course of orthodontic treatment may be useful in predicting compliance, for example, age, postcode, standard of oral hygiene and dental health component of the Index of Orthodontic Treatment Need (IOTN) ${ }^{(5)}$. Normative measures such as this, however, that do not account for patient factors, are unlikely to give much useful predictive information. Oral health-related quality of life measures are useful in addition to clinical measures alone as they add to our information by taking into account patient perceptions.

Perhaps these newer quality of life measures and measures of orthodontic aesthetic impact could be useful in conjunction with the aesthetic component of IOTN to predict good compliers. The aesthetic component of IOTN is a series of pictures of malocclusions graded in increasing order of severity from 1 to 10 . Although there is little research on quality of life measures in dentistry, and especially orthodontics and malocclusion, there has been a considerable amount of pioneering work in the medical field during the last 20 years. In orthodontics, quality of life changes have been studied more in relation to orthognathic surgery than orthodontics $^{(6)}$. However, O'Brien, Kay, Fox et $a l^{(7)}$ investigated the possibility of using utility values for assessing oral health outcomes in orthodontics. Utility values are cardinal values assigned to health states. They represent the values that individuals hold for certain states of health or disease. They asked the question: are non-seekers unable to perceive the extent of their malocclusion, or do they perceive their teeth in the same way as seekers, but simply make different judgements about the most appropriate actions to take? This study showed that utility values, derived by a time trade-off technique using the aesthetic component of IOTN were different for seekers of treatment and non-seekers of treatment (Figure 1).

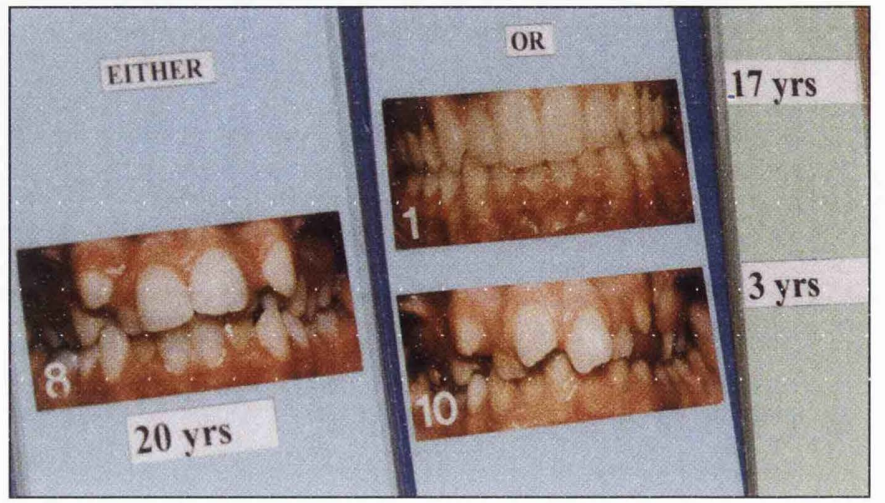

Figure I

The oral aesthetic subjective impact scale (OASIS) $)^{(8)}$ includes a series of questions to assess the degree of concern or disadvantage children perceived because of the arrangement of their teeth. The questions, aimed to quantify how the subject felt about their teeth, were scored on a Likart scale. This data and the subject's own assessment of the aesthetic component of IOTN for their malocclusions was used to 
calculate the subject's OASIS score. Each patient assessed his or her own malocclusion on the aesthetic component of IOTN (Figure 2).

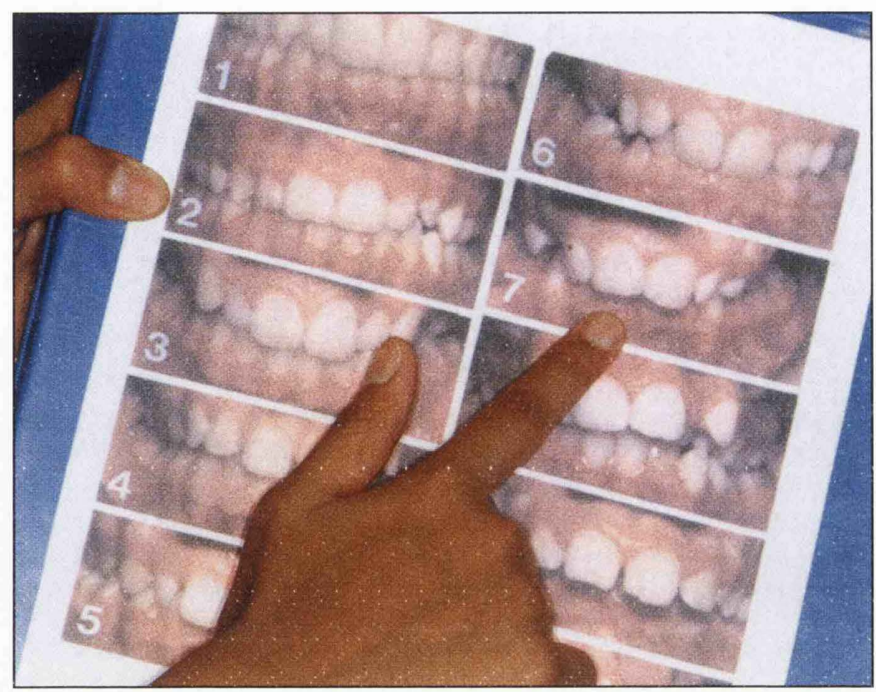

Figure 2

\section{METHOD}

I wanted to find out if these quality of life measures and measures of orthodontic aesthetic impact would be useful in conjunction with IOTN to predict good compliers. This question was the focus of the study. For an instrument to be useful in measuring quality of life it should include factors about feelings, appearance and teasing. Quality of life measures used in this study were OASIS and Utility Scores, both of which included these factors.

The study design was a prospective, cohort study. One hundred and fifty-five subjects were consented into the study at six centres: 1 dental hospital, 4 district general hospitals, and 1 specialist practice. At the start of treatment age and gender were recorded. A questionnaire to record sociodental information was completed by all subjects.

The utility values were measured with features of the aesthetic component of IOTN and a time trade-off technique (Figure 1). The subject expressed the number of years they would be prepared to trade off a poor appearance to ultimately achieve a good appearance. From this data a utility score was calculated. Previous work on utility values has shown that children who seek treatment think differently about their teeth compared to those who do not. Home postcode was noted and used to calculate a Townsend score, a measure of social deprivation ${ }^{(9)}$. The higher the score the more deprived the subject.

Cooperation during treatment was assessed, visit by visit, by the treating clinician and measured on a $5 \mathrm{~cm}$ Likert scale, from 'very poor' to 'excellent'. The values were summed and a mean compliance score calculated for each subject. The most compliant patients had the highest score. Additionally the operator was asked to record a plaque score on certain teeth at the start of treatment and again at every sixth visit, mesial, distal, gingival and incisal to the appliance bracket.

At the end of treatment the number of failed or cancelled appointments and the number of breakages were recorded. We also noted if the patient completed the treatment, how long it took and the type of appliance used.

\section{RESULTS}

The research question was concerned with the interaction of several variables. First, descriptive statistics were used and the data checked for normality. Multiple regression analysis models were calculated as appropriate using logistic regression for non-parametric data and linear models for parametric dependant variables. It was calibrated for IOTN and statistics were calculated for the calibration and intraexaminer reliability.

So, what did the study find out? The mean age at the start of treatment was 13 years and 10 months. The gender mix was $47.4 \%$ boys and $52.6 \%$ girls. Treatment was completed for $54.1 \%$ of subjects and the average Townsend score was 2.2. A fixed appliance was used most often.

In summary, this study found that the clinical factors such as the presence of a fixed appliance indicated better general compliance and start plaque scores could be used to predict compliance with treatment. Conversely, sociodental indicators (OASIS and Utility scores) were generally not useful in predicting patient compliance.

\begin{tabular}{|l|l|l|l|l|}
\hline $\begin{array}{l}\text { Dependant } \\
\text { variable }\end{array}$ & $\begin{array}{l}\text { Independent } \\
\text { variable }\end{array}$ & $\mathrm{B}$ value & $\mathrm{P}$ value & \\
\hline $\begin{array}{l}\text { Treatment } \\
\text { complete }\end{array}$ & $\begin{array}{l}\text { Fixed } \\
\text { appliance }\end{array}$ & 2.04 & 0.001 & $\begin{array}{l}\text { Odds ratio } \\
7.95\end{array}$ \\
\hline & $\begin{array}{l}\text { Utility value } \\
\text { for AC 5 }\end{array}$ & 0.14 & 0.053 & $\begin{array}{l}\text { Odds ratio } \\
1.15\end{array}$ \\
\hline $\begin{array}{l}\text { Compliance } \\
\text { (Likert scale) }\end{array}$ & $\begin{array}{l}\text { Start plaque } \\
\text { score }\end{array}$ & $-7.95 \mathrm{E}-02$ & 0.014 & $\begin{array}{l}\mathrm{R}^{2} \\
0.18\end{array}$ \\
\hline & $\begin{array}{l}\text { Fixed } \\
\text { appliance }\end{array}$ & -0.58 & 0.007 & $\begin{array}{l}\mathrm{R}^{2} \\
0.26\end{array}$ \\
\hline & $\begin{array}{l}\text { Townsend } \\
\text { score }\end{array}$ & $5.93 \mathrm{E}-02$ & 0.014 & $\begin{array}{l}\mathrm{R}^{2} \\
0.33\end{array}$ \\
\hline
\end{tabular}

Table 2 Completion of and compliance with treatment

The upper part of Table 2 shows logistic regression. The type of appliance was found to influence compliance. If a patient wore a fixed appliance the odds ratio shows that they were eight times more likely to complete treatment. This is statistically significant $(\mathrm{P}=0.001)$. The presence of a fixed appliance accounted for $26 \%$ of the variability in compliance.

The utility value for AC 5 shows that the subject was less likely to accept their malocclusion and therefore 1.2 times more likely to complete treatment $(\mathrm{P}=0.053)$.

The lower half of Table 2 shows linear regression. Because of the negative $B$ value the higher the start plaque the less overall compliance. Plaque scores at the start of treatment were shown by this study to predict compliance for the whole of treatment. The higher the plaque score at the start of treatment the less compliant the subject is likely to be during treatment. Plaque score accounted for $18 \%$ of the variability $\left(R^{2}=0.18\right)$.

Patients wearing a fixed appliance were more likely to be compliant. The more deprived the subject, the more compliant $(\mathrm{P}=0.007)$. This is surprising as an additional finding was that the more deprived subjects had higher midtreatment plaque scores. This finding may be due to bias on the part of the orthodontist. Social factors that predominate in certain neighbourhoods may have influenced the orthodontist to rate compliance higher by judging that the subject had more difficult social problems to overcome. In a paper by Kenealy and Shaw ${ }^{(10)}$ they report that middle class children 
were more likely to request treatment. However, this study suggests that even though demand for treatment may be higher in middle class children they do not necessarily comply better with treatment.

$\mathrm{R}$ squared values, which explain the variability in compliance predicted by these variables, are fairly low, so other factors must be operating to influence compliance.

\begin{tabular}{|l|l|l|l|l|}
\hline $\begin{array}{l}\text { Dependant } \\
\text { variable }\end{array}$ & $\begin{array}{l}\text { Independent } \\
\text { variable }\end{array}$ & B value & P value & R square \\
\hline $\begin{array}{l}\text { Mid-treatment } \\
\text { plaque score }\end{array}$ & $\begin{array}{l}\text { Townsend } \\
\text { score }\end{array}$ & 0.86 & 0.001 & 0.16 \\
\hline & Gender & -4.88 & 0.013 & 0.27 \\
\hline $\begin{array}{l}\text { Number of } \\
\text { breakages }\end{array}$ & $\begin{array}{l}\text { Avoidance } \\
\text { of smiling }\end{array}$ & -2.28 & 0.016 & 0.08 \\
\hline & IOTN at start & -0.49 & 0.043 & 0.14 \\
\hline
\end{tabular}

Table 3 Plaque score and breakages during treatment

Table 3 shows that boys had higher mid-treatment plaque scores than girls. The higher the Townsend score, the higher the mid-treatment plaque score. Twenty-seven per cent of the variability in mid-treatment plaque score could be accounted for by gender and $16 \%$ by Townsend score.

Subjects who avoided smiling more because of the appearance of their teeth had fewer breakages during treatment. The table also shows that subjects with a worse malocclusion at the start of treatment had fewer breakages during treatment. Generally, though, the $\mathrm{R}^{2}$ values are still low. Social deprivation accounted for only $16 \%$ of the variability.

\section{DISCUSSION}

It was generally surprising that the predictors of midtreatment compliance and overall compliance in this study were limited to factors such as gender, social deprivation, type of appliance, severity of malocclusion and start plaque score with generally no influence of the sociodental factors assessed.

Sociodental variables (OASIS and utility scores) appeared to have only a limited predictive effect in terms of whether the treatment was completed or not and on the number of appliance breakages. It is, therefore, questionable whether it is worthwhile collecting additional sociodental data on all our patients when it seems that we can predict cooperation from sociodemographic and clinical data alone.

So what does all this mean in clinical orthodontic practice? Have my findings changed my clinical practice? Yes: since cooperation with orthodontic treatment is more likely to be influenced by clinical factors such as type of appliance, severity of malocclusion and plaque score at the start of treatment, I can assess these factors before treatment starts. I am more likely to be successful when using a fixed appliance than a removable type. Also, if the malocclusion is not particularly severe or the patient unconcerned by the arrangement of their teeth I can be alert to the possibility of problems. If the patient is not able to demonstrate a high standard of toothbrushing and oral hygiene it is unlikely that their treatment will be completed satisfactorily.

The question about avoidance of smiling could be a useful indicator at the start of treatment of compliance and further investigation may be interesting. The question could be routinely included in new patient clinics.
Sociodental indicators such as OASIS score and utility values are generally not effective as predictors of cooperation. They may be more effective as indicators in other areas of orthodontics, for example population-based research and manpower planning, rather than patient-based studies. An effect of socio-economic status and gender on cooperation with treatment is shown but it is debatable whether this information will influence access to care.

Perhaps we now have the scientific ability to pick losers in advance!

Acknowledgments: I would like to thank the following people who assisted with and funded this study. Dr. Nicky Mandall for her helpful, logical advice and constant encouragement, for her realistic goal-setting throughout this thesis and for treating many of the patients in the study. Without the collection of data there would be no results. My grateful thanks to Dr Dee Fox of St Anne's Orthodontic Practice, Dr Jonathan Miller at Manchester Dental Hospital and the Clinical Assistants at Royal Bolton Hospital who carried out the treatment. Dr Fox provided the TTO flip chart used during the initial patient consultations. I am grateful to Dr Helen Worthington for her invaluable advice with the statistical analysis and to Jean Wright for calculating the Townsend Scores. Thank you to the NHS Research and Development programme for funding this study. Without the unfailing support of my husband John, sons, Robert, Peter and David and my father Angus this work would never have reached completion. Thank you all very much.

\section{REFERENCES}

1 Dental Practice Board. Statistical Department, Crompton Place Road, Eastbourne, East Sussex. 2002

2 Haynes S. Discontinuation of orthodontic treatment in the General Dental Services in England and Wales 1972-1979. Br Dent J 1982;152:127-129

3 Richmond S, Andrews M. Discontinued orthodontic treatment in the General Dental Services of England and Wales (1990-1991). Br J Orthodont 1995;22:263-268

4 Murray AM. Discontinuation of orthodontic treatment: a study of the contributing factors. $\mathrm{Br} \mathrm{J}$ Orthod $1989 ; 1989(16) ; 1-7$

5 Shaw WS, Richmond S, O'Brien KD, Brook P, Stephens CD. Quality control in orthodontics: Indices of treatment need and treatment standards. Br Dent J 1991;170:107-112

6 Cunningham SJ, Hunt NP. Quality of life and its importance in orthodontics. J Orthodont 2001;28:152-158

7 O'Brien K, Kay E, Fox D, Mandall, N. Assessing oral health outcomes for orthodontics-measuring health status and quality of life. Comm Dent Health 1998;15:22-26

8 Mandall N A, McCord JF, Blinkhorn AS, Worthington HV, O'Brien K D. Perceived aesthetic impact of malocclusion and oral self-perceptions in 14-15 year old Asian and Caucasian children in Greater Manchester. Eur J Orthodont 1999;21:175-183

\section{Townsend P. Deprivation. J Soc Policy 1987;16:125-146}

10 Kenealy P, Shaw WC. The influence of social class on the uptake of orthodontic treatment. Br J Orthodont 1989;16:107111 